\title{
The continuous suture in cataract surgery and its effect on intraocular pressure
}

\author{
A. F. HARDEN AND I. MaL. NORTH*
}

The St. John Ophthalmic Hospital, Jerusalem

The continuous suturing technique is widely used in ophthalmology, but curiously there are few references to its use in cataract surgery. The purpose of this study was to assess this technique and to observe its effect on the intraocular pressure.

\section{Technique}

Two methods of continuous suturing were studied: the continuous interlocking suture and the continuous over-and-over suture (Figs. I and 2).

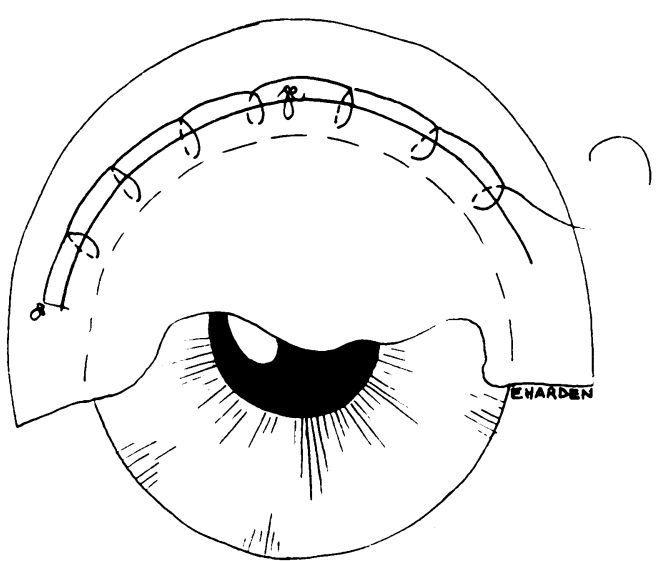

F I G. I Continuous interlocking suture

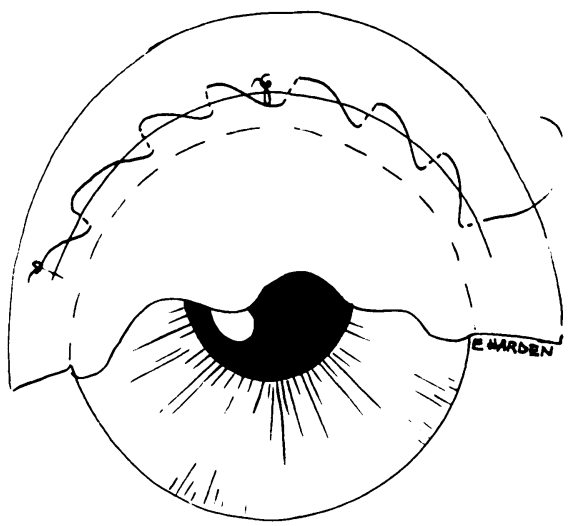

FIG. 2 Continuous over-and-over suture

REMOVAL OF LENS

The lens was removed using the $a b$ externo approach with a limbal-based flap and corneo-scleral section, followed by a round pupil cryoextraction with or without zonulysin. The zonulysin used was 0.5 to $\mathrm{I}$ ml. Chymozym (Ikapharm) containing ${ }_{16} 6{ }_{3}$ to $33^{2}$ Anson proteolytic units. Postoperatively the patients received atropine and antibiotic drops. Steroid drops were started on the third postoperative day.

WOUND GLOSURE

With each technique, a single 12 o'clock pre-placed 8/o black silk safety suture on an atraumatic needle was inserted initially. This was removed on completion of wound closure. Continuous suturing, using the same material, was commenced at the 9.30 o'clock position, the suture end being tied here. Passing the needle from cornea to sclera, 6 to 8 evenly spaced $2 / 3$ depth bites perpendicular to the section were made. The suture was completed by a tie at the 2.30 o'clock 
position. Before the final tie was made, the suture was tightened beginning at 9.30 o'clock to ensure good wound closure. 50 per cent of the continuous sutures were interlocked (Table I) and 50 per cent were over-and-over (Table II).

Table I Preoperative and postoperative (2, 5, 20, and 40 days) tensions in 25 cases in which the continuous interlocking suture was used

\begin{tabular}{|c|c|c|c|c|c|}
\hline \multirow{2}{*}{$\begin{array}{l}\text { Preoperative } \\
\text { tension } \\
(\mathrm{mm} . \mathrm{Hg})\end{array}$} & \multirow{2}{*}{$\begin{array}{l}\text { Zonulolysis } \\
+-\end{array}$} & \multicolumn{4}{|c|}{ Postoperative tension ( $\mathrm{mm} . \mathrm{Hg}$ ) } \\
\hline & & 2 & 5 & 20 & 40 \\
\hline 21 & + & 8 & 8 & 5 & 17 \\
\hline 20 & + & 18 & 17 & 20 & 18 \\
\hline 20 & + & 12 & 16 & 10 & \\
\hline 18 & + & 12 & 8 & 4 & \\
\hline 18 & + & 6 & 8 & 8 & \\
\hline 18 & + & 32 & 26 & 10 & 18 \\
\hline 18 & - & 16 & Fai & w up & \\
\hline 16 & + & 26 & 10 & 18 & \\
\hline 16 & - & 8 & 15 & 15 & \\
\hline 16 & - & 8 & 10 & 12 & \\
\hline 15 & + & 21 & 12 & 10 & \\
\hline 14 & + & 13 & 10 & 10 & 13 \\
\hline 14 & + & 14 & & 10 & \\
\hline 14 & + & 6 & 4 & 2 & 10 \\
\hline I 3 & - & 16 & & 6 & \\
\hline 13 & - & 10 & 8 & 5 & \\
\hline 12 & + & 10 & 20 & 12 & \\
\hline 12 & + & 12 & & 8 & \\
\hline 12 & - & 13 & 13 & 13 & \\
\hline 12 & - & 10 & 10 & 10 & \\
\hline II & + & 10 & 8 & 4 & \\
\hline 10 & + & 10 & 12 & 15 & 10 \\
\hline 10 & + & 8 & 16 & Failed & ow up \\
\hline 8 & - & 8 & & 8 & \\
\hline 7 & - & 10 & 8 & 4 & \\
\hline
\end{tabular}

INTRAOCULAR PRESSURE MEASUREMENT

In all cases, the tension was measured with the Goldmann applanation tonometer preoperatively. 2 days postoperatively, 5 days postoperatively, and at subsequent clinic visits. 
Table II Preoperative and postoperative tensions in 25 cases in which the continuous over-and-over suture was used

\begin{tabular}{|c|c|c|c|c|c|}
\hline \multirow{2}{*}{$\begin{array}{l}\text { Preoperative } \\
\text { tension } \\
(\mathrm{mm} . \mathrm{Hg})\end{array}$} & \multirow{2}{*}{$\begin{array}{l}\text { Zonulolysis } \\
+-\end{array}$} & \multicolumn{4}{|c|}{ Postoperative tension ( $\mathrm{mm} . \mathrm{Hg}$ ) } \\
\hline & & 2 & 5 & 20 & 40 \\
\hline 21 & - & 20 & 20 & 22 & \\
\hline 20 & - & 4 & o & 6 & 20 \\
\hline 19 & + & 20 & 12 & 15 & 15 \\
\hline 18 & + & 6 & 6 & Los & ow up \\
\hline 18 & + & 14 & 10 & 10 & \\
\hline I 7 & + & 10 & & 15 & \\
\hline 17 & - & 20 & 18 & 10 & \\
\hline 17 & - & 12 & Io & 12 & 18 \\
\hline I6 & - & 12 & 12 & 10 & 10 \\
\hline 16 & + & Io & 7 & 12 & 12 \\
\hline 16 & + & 28 & 18 & 10 & 18 \\
\hline 15 & - & 12 & IO & 10 & \\
\hline 14 & + & 14 & 10 & 20 & \\
\hline 14 & + & 23 & 21 & 15 & \\
\hline 14 & + & 15 & 15 & 12 & \\
\hline 14 & + & 8 & I0 & 10 & \\
\hline 14 & + & 10 & Io & 10 & \\
\hline 14 & + & 26 & & 24 & 4 \\
\hline 14 & - & 10 & 12 & 17 & \\
\hline 14 & - & 10 & Io & 5 & \\
\hline 12 & + & 12 & & 10 & \\
\hline 12 & + & 22 & 20 & 9 & \\
\hline 12 & + & 17 & & & 2 \\
\hline 12 & - & 20 & I 4 & 12 & \\
\hline 8 & - & 20 & 16 & 8 & \\
\hline
\end{tabular}

RESULTS

As the technique is not well documented, the patients chosen were those with uncomplicated cataract. Fifty cases were studied.

The Tables show that the postoperative tensions were slightly higher with the continuous overand-over suture (Table II) than with the interlocking suture (Table I). In only five cases did the tension exceed $24 \mathrm{~mm}$. $\mathrm{Hg}$, and it was never more than $32 \mathrm{~mm}$. $\mathrm{Hg}$. These high tensions occurred in the early postoperative period in eyes in which zonulysin had been used. All but two had returned to normal by the $5^{\text {th }}$ postoperative day. One of these was normal by the first clinic visit, and the other by the second. Some of the eyes showed a marked hypotension. 
No serious complications were encountered. Flat anterior chambers occurred in two cases; one patient required surgery and had a satisfactory outcome and the other, who presented on the 2oth postoperative day, refused further treatment and was lost to follow up. In neither case could we attribute the flat chamber to the suturing technique.

\section{Discussion}

Williams (1866) was the first to describe the use of sutures in cataract surgery. At this time the routine cataract extraction was extracapsular and the wound small. With the advent of the intracapsular extraction, larger sections were required, and at that time sutures, needles, and instruments were inadequate. These improved, enabling safe wound closure, initially with only one suture. With further refinements more sutures have been inserted into the cataract section. Scheie (1959) excellently reviewed the history of the incision and closure of the cataract section. Today, five or more interrupted sutures are generally used in wound closure. In the English medical literature we could find no detailed reference to the continuous over-and-over suture. Pierse and Condon ( I968) mentioned continuous suturing without describing it in detail. Ryan and Maumenee (I97I) described the technique of the continuous interlocking suture. In the European medical literature there have been several references to the continuous suturing technique (Strampelli, I962; Jaroszynski, ı966; Boke, Thiel, and Jonck, r969; Giessmann and Schlote, I970), but no detailed studies of its effect on the intraocular pressure.

The behaviour of the intraocular pressure after cataract surgery using interrupted sutures has been well documented (Hilding, I955; Galin, Baras, and Perry, I 96 I ; Giardini and Paliaga, I964; Miller and Morin, r 968), and the eye has been reported to be nor motensive or hypotensive. An occasional case of hypertension occurred. The use of thee continuous suture produced a similar pattern of intraocular pressure. A possible explana-? tion for the slight difference in intraocular pressure after the use of the continuous interlocking and the over-and-over suture is that wound leakage has occurred with the former. We noted that, when the section was closed, on lifting the conjunctival flap, the lips of the wound tended to separate more with the interlocking than with the over-and-over suture. We found no clinical evidence of this leakage.

There are conflicting reports in the literature of the relationship between the intraocular pressure after cataract extraction and the use of zonulysin. Some authors recorded ocular hypertension in a high percentage of cases in which zonulysin was used (Kirsch, i 964; Galin, Barasch, and Harris, I 966). Others (Garcia-Sánchez and Sánchez-Salorio, I 969) found no rise in the intraocular pressure. The former authors used larger amounts of zonulysin. Kirsch (1966) showed a relationship between the amount of zonulysin used and the postoperative intraocular pressure, but occasional rises were seen even with small doses. Our five cases in which the tension exceeded $24 \mathrm{~mm}$. $\mathrm{Hg}$ had had zonulysin, and as our dosage was similar to that of Garcia-Sánchez and Sánchez-Salorio (1969), our findings tend to support those of Kirsch (1966).

\section{Advantages and disadvantages of the continuous suture}

With the continuous suture, adequate wound closure is obtained more speedily than with interrupted sutures as only two knots are tied. Also the eyes remain quieter, possibly because there are fewer knots. We hoped that the sutures would remain covered by the 
conjunctival flap, but in 20 per cent of cases the knots became exposed and had to be removed. We believe that, with less reactive suture material, even quieter eyes may be obtained.

One of the problems encountered was the closure of the bulging wound, as the suture is truly post-placed. This difficulty was minimized by the use of the 12 o'clock safety suture, which also had the advantage of ensuring correct wound alignment. With the continuous suture two vectors of force are present, one across the section and the other along it, and the balance of these forces is most critical when the final knot is tied. If the balance is incorrect, radiating tension folds occur in the cornea, but these can be prevented by paying careful attention to maintaining even tension.

Theoretical problems with this technique are suture breakage or the cutting out of a bite. At the time of surgery these can be recognized and dealt with, but if they occur in the early postoperative period the complications of an open section may arise; these complications did not occur in our series.

\section{Summary}

Two techniques of continuous suturing in cataract surgery are described and their advantages discussed. Their effect on the intraocular pressure in a series of fifty cases was found to be closely similar to that of the interrupted suture.

We should like to thank the Grand Priory in the British Realm of the Most Venerable Order of the Hospital of St. John of Jerusalem for the opportunity to undertake this study, and the Warden, Dr. Batten, for his co-operation.

\section{References}

BÖKE, W., THIEL, H. J., and JöNCK, M. (I969) Ber. dtsch. ophthal. Ges., 70, 95

galin, M. A., BARAsch, K. R., and harris, L. s. (ig66) Amer. J. Ophthal., 6r, 690

- BARAS, I., and PERry, R. (196I) A.M.A. Arch. Ophthal., 66, 8o

GARCIA-SÁNCHEZ, J., and SÁNChEZ-SALORIO, M. (1969) An. Inst. Barraquer, 9, I87

giardini, A., and Paliaga, G. P. (1964) Brit. 7. Ophthal., 48, 133

giessmann, H. G., and schlote, H. w. (r970) Klin. Mbl. Augenheilk., r57, 543

hilding, A. C. (1955) A.M.A. Arch. Ophthal., 53, 686

JAROSzYŃskr, G. (ig66) Klin. oczna, 36, 443

KIRSGH, R. E. (1964) Arch. Ophthal. (Chicago), 72, 61 2

$$
\text { ( } 1966) \text { Ibid., 75, } 774
$$

Miller, J. R., and morin, J. D. (I968) Amer. F. Ophthal., 66, 523

PIERSE, D.. and condon, P. I. (I968) Trans. ophthal. Soc. U.K., 88, 4I 5

Ryan, s. J., and maumenee, A. E. (I97I) Arch. Ophthal. (Chicago), 85, 302

sGHeIE, H. G. (1959) A.M.A. Arch. Ophthal., 6r, 43 I

STRAMPelli, B. (I962) Ann. Ottal., 88, 423

williams, H. w. (1866) "Recent Advances in Ophthalmic Science", p. 9o. The Boylston Prize

Essay for 1865. Ticknor and Fields, Boston

\section{Addendum}

Using the over-and-over continuous suture with the microscope and ro/o Perlon, one of us (A.H.) has found in a small series a repeated rise in the intraocular pressure. This difference is presumed to be due to the perfect wound apposition and closure obtainable with microscopic control. 